\title{
The effect of using limited scene-dependent averaging kernels approximations for the implementation of fast observing system simulation experiments targeted on lower tropospheric ozone
}

\author{
P. Sellitto ${ }^{1}$, G. Dufour ${ }^{1}$, M. Eremenko ${ }^{1}$, J. Cuesta ${ }^{1}$, V.-H. Peuch ${ }^{2}$, A. Eldering ${ }^{3}$, D. P. Edwards ${ }^{4}$, and J.-M. Flaud ${ }^{1}$ \\ ${ }^{1}$ Laboratoire Inter-universitaire des Systèmes Atmosphériques, CNRS - UMR7583, Universités Paris-Est et Paris Diderot, \\ CNRS, 61 Avenue du Général de Gaulle, 94010 Créteil, France \\ ${ }^{2}$ European Centre for Medium-Range Weather Forecasts (ECMWF), Research Department, Shinfield Park, Reading, \\ Berkshire, RG2 9AX, UK \\ ${ }^{3}$ Jet Propulsion Laboratory, California Institute of Technology, Pasadena, California, USA \\ ${ }^{4}$ National Center for Atmospheric Research, Boulder, Colorado, USA \\ Correspondence to: P. Sellitto (pasquale.sellitto@lisa.u-pec.fr)
}

Received: 15 February 2013 - Published in Atmos. Meas. Tech. Discuss.: 8 March 2013

Revised: 19 June 2013 - Accepted: 29 June 2013 - Published: 5 August 2013

\begin{abstract}
Practical implementations of chemical OSSEs (Observing System Simulation Experiments) usually rely on approximations of the pseudo-observations by means of a predefined parametrization of the averaging kernels, which describe the sensitivity of the observing system to the target atmospheric species. This is intended to avoid the use of a computationally expensive pseudo-observations simulator, that relies on full radiative transfer calculations. Here we present an investigation on how no, or limited, scene dependent averaging kernels parametrizations may misrepresent the sensitivity of an observing system. We carried out the full radiative transfer calculation for a three-days period over Europe, to produce reference pseudo-observations of lower tropospheric ozone, as they would be observed by a concept geostationary observing system called MAGEAQ (Monitoring the Atmosphere from Geostationary orbit for European Air Quality). The selected spatio-temporal interval is characterised by an ozone pollution event. We then compared our reference with approximated pseudo-observations, following existing simulation exercises made for both the MAGEAQ and GEOstationary Coastal and Air Pollution Events (GEOCAPE) missions. We found that approximated averaging kernels may fail to replicate the variability of the full radiative transfer calculations. In addition, we found that the approximations substantially overestimate the capability of MAGEAQ to follow the spatio-temporal variations of the
\end{abstract}

lower tropospheric ozone in selected areas, during the mentioned pollution event. We conclude that such approximations may lead to false conclusions if used in an OSSE. Thus, we recommend to use comprehensive scene-dependent approximations of the averaging kernels, in cases where the full radiative transfer is computationally too costly for the OSSE being investigated.

\section{Introduction}

Observing System Simulation Experiments (OSSEs) are a class of sensitivity analyses that can be used to evaluate the expected added value of a future observing system. The construction of an observing system involving new instruments can be very costly, especially when dealing with satellites. Then, an objective evaluation of the potential impact of a future satellite observing system is desirable, during the design phase, to select and set-up these costly systems (Masutani et al., 2010b). Historically, OSSEs were first used to evaluate the impact of new observations on numerical weather predictions (Arnold and Clifford, 1986; Lahoz et al., 2005; Tan et al., 2007; Masutani et al., 2010a). Recently, OSSEs have been carried out to analyse the expected added value of future satellite missions on trace gases monitoring (Edwards et al., 2009; Claeyman et al., 2011a; Zoogman et al., 2011).

Published by Copernicus Publications on behalf of the European Geosciences Union. 
Edwards et al. (2009) called these sensitivity analyses chemical OSSES.

A chemical OSSE is composed of three elements (Edwards et al., 2009): the Nature Run (NR), the PseudoObservations (POs) simulator, and the assimilation scheme leading to the Assimilation Run (AR) by means of the assimilation of the POs in a Control Run (CR). The NR is used to produce the truth of our simulation world, or the pseudoreality (Masutani et al., 2010b). The NR defines the reality that we wish to characterise with the POs. The synthetic observations are produced by means of a PO simulator. The PO simulator samples the NR, simulates the spectral measurements as they would be done by the evaluated instrument concept and then inverts the spectra to give the PO of the chosen geophysical quantity and its associated error characterisation, as the final output. A full description of the simulated instrument must be given at this stage (Edwards et al., 2009). Then, the POs are assimilated into the $C R$. The $C R$ is an alternative representation of the true atmosphere, usually given by a model different from the NR. It is intended to be a parallel in our simulation world of how a model or a priori information (e.g. a climatology) would represent the real world. The obtained AR mimics, in our simulation world, the assimilation of real observations into a chemistry and transport model (or another kind of model) to obtain a model analysis and forecast. Finally, the AR can be compared with the NR and the CR, to evaluate the impact of the POs in providing useful information about the pseudo-reality defined by the NR.

At the core of a chemical OSSE is the production of a set of POs that fully describe the measurements of a future observing system. The most rigorous way to do this is to use a radiative transfer model and an inversion algorithm to perform full and accurate forward and inverse radiative transfer (RT) calculations. When dealing with OSSEs over extended periods of time and/or large spatial regions, simulating complex instrumental/multi-instrumental configurations, which may involve large input vectors to the inversion scheme or complex inversion algorithms, the computational cost can be prohibitive. In addition, studies of observing systems with a high revisit time, which is the case with geostationary instruments, can further increase the data volumes to be analysed. In practical implementations of chemical OSSEs, approximated PO simulators are often used, see e.g. Claeyman et al. (2011a); Zoogman et al. (2011). The idea is to avoid the full RT calculations by a predefinition of typical averaging kernels (AKs) aimed at describing the vertical sensitivity of the observing system. The NR fields are then sampled with the observation geometry of the instrument and a simple convolution with these typical AKs leads to the approximated POs.

However, the AKs variability can be large, and their shape and magnitude can depend on several NR parameters. It is thus reasonable to expect that the AKs and the sensitivity of the PO can be strongly scene-dependent. This variability in the AKs is likely underestimated by using the type of approximations mentioned above. Very few examples exist of PO approximations with a limited partial consideration of scene characterisation. For example, Claeyman et al. (2011a) carried out a simplified OSSE using a look-up-table of precalculated AKs matrices parameterized as a function of NR thermal contrast between the surface temperature and nearsurface air temperature. The thermal contrast has been considered the most important parameter for the problem under investigation, i.e. the observation of lower tropospheric (LT) ozone information with thermal infrared geostationary instruments. It is still to be verified if a limited scenedependence, like the one described in the above lines, can lead to satisfactory approximations.

In this paper, we address the problem of carrying out fast OSSEs with parameterized AKs. We investigate the degree to which the limited scene-dependence of PO approximations can be representative of the expected spatial and temporal variability of the observing system sensitivity, if compared to a reference set of POs produced with full RT calculations. Our simulation exercise is based on LT ozone column retrievals (from surface to 6 or $3 \mathrm{~km}$ ) obtained from thermal infrared spectral measurements for the concept geostationary instrument MAGEAQ (Monitoring the Atmosphere from Geostationary orbit for European Air Quality) (Peuch et al., 2010; Claeyman et al., 2011b).

This paper is structured in the following way. In Sect. 2, we describe the dataset used, for both the full RT and the approximated POs. In Sect. 3.1 we test the capability of the approximations to replicate the variability of the AKs of the full RT calculations and related quantities. In Sect. 3.2 we discuss how the approximated POs can replicate the LT ozone spatio-temporal distributions, in particular in the presence of an ozone pollution event. Finally, conclusions are given in Sect. 4. A list of the abbreviations used in this paper is in Appendix A.

\section{Datasets description}

Our exercise is targeted on ozone retrievals at the lowest altitudes, i.e. at altitudes important for air quality (Amann et al., 2005). With this aim, we have produced both full RT and approximated POs of surface- $6 \mathrm{~km}$ and surface- $3 \mathrm{~km}$ ozone partial columns. The effect of clouds is not considered in our study. In the following, we describe the common baseline of the full and approximated simulations, and then the different datasets.

\subsection{Common set-up of the simulations}

The NR is produced by means of the MOCAGE (MOdèle de Chimie Atmosphérique à Grande Echelle) chemistry and transport model (Dufour et al., 2005). MOCAGE simulates the physics and chemistry of gases and aerosols in both the troposphere and the stratosphere, by using 47 hybrid 
vertical levels, from surface to about $35 \mathrm{~km}$ (Dufour et al., 2005). The vertical resolution of the simulated fields is about $200 \mathrm{~m}$ in the troposphere increasing up to about $1 \mathrm{~km}$ in the stratosphere. The horizontal grid in our region of study is $0.2^{\circ} \times 0.2^{\circ}$. The chemical scheme used by MOCAGE simulations is RACMOBUS, which is a combination of the REPROBUS scheme (in stratosphere) (Lefèvre et al., 1994) and the RACM scheme (in troposphere) (Stockwell et al., 1997).

As a test observing system for our exercise, we have chosen a concept geostationary observing system called MAGEAQ (Peuch et al., 2010; Lahoz et al., 2012). MAGEAQ is a multi-spectral instrument being designed to provide information on air quality over Europe, with a relevant spatio-temporal resolution. The principal science objective of MAGEAQ is to better characterise spatio-temporal variations of lower tropospheric pollutants like the ozone or the carbon monoxide over Europe. MAGEAQ is composed of two instrumental elements, a hyperspectral thermal infrared spectrometer and a visible broadband radiometer. MAGEAQ was a candidate for the ESA's Earth Explorer 8 call for proposals, but not selected. Owing to its high spectral resolution $\left(0.05 \mathrm{~cm}^{-1}\right)$ and small radiometric noise $\left(6.04 \mathrm{nW}\left(\mathrm{cm}^{2} \mathrm{srcm}^{-1}\right)^{-1}\right)$ in the infrared ozone band, it is meant to be dedicated to ozone retrieval in the lowermost troposphere (Claeyman et al., 2011b). In the present study only the thermal infrared part of the MAGEAQ observing system will be considered. As for the geometry of observation, a sub-satellite point at latitude $=0$ and longitude $=0$ and the threshold configuration of MAGEAQ are considered (Peuch et al., 2010), with a horizontal resolution of $15 \mathrm{~km} \times 15 \mathrm{~km}$ at sub-satellite point, and a field of regard of $\left(15^{\circ} \mathrm{W}-35^{\circ} \mathrm{E}\right.$, $35^{\circ} \mathrm{N}-65^{\circ} \mathrm{N}$ ).

\subsection{Full radiative transfer calculations}

We produced a set of reference synthetic full RT observations by means of our PO simulator. The PO simulator is more thoroughly described by Sellitto et al. (2013).

The NR is sampled by a simulator of geostationary observations geometry to simulate the MAGEAQ viewing angles and the geometrical parameters used as inputs for the radiative transfer model.

A radiative transfer model is then used to simulate the spectra observations for each scene. As the forward radiative transfer model we use the Karlsruhe Optimized and Precise Radiative transfer Algorithm (KOPRA) (Stiller et al., 2002), adapted to the nadir geometry (Eremenko et al., 2008). The MAGEAQ observing system is simulated taking into account its spectral resolution, radiometric noise and observation geometry.

The simulated spectra are then inverted by means of the KOPRAfit retrieval module (Hoepfner et al., 2001) embedding an altitude-dependent Tikhonov-Phillips regularisation method. Kulawik et al. (2006) first introduced altitude-dependent constraint matrices in regularisation schemes for the retrieval of trace gases vertical profiles. The regularisation method used in our simulator has been optimised for lower tropospheric ozone observations using IASI (Infrared Atmospheric Sounding Interferometer) measurements (Eremenko et al., 2008). This inversion algorithm uses seven spectral micro-windows in the range $975-1100 \mathrm{~cm}^{-1}$ to avoid carbon dioxide and water vapour impact on the ozone retrievals. This algorithm minimises a cost function calculated with the degrees of freedom of the signal (DOF) and the error in the lower troposphere, aimed at the maximisation of the sensitivity in the lower troposphere while retaining a reasonable error (Eremenko et al., 2008; Dufour et al., 2012). The KOPRAfit also provides the AKs, that can be used to derive the information on the vertical sensitivity of the observations to the "true" NR ozone profile. We used the climatology of McPeters et al. (2007) for the ozone a priori profiles.

Three days (19-21 August 2009) of POs on a $1 \mathrm{~h}$ revisit time basis over Europe $\left(15^{\circ} \mathrm{W}-35^{\circ} \mathrm{E}, 35^{\circ} \mathrm{N}-65^{\circ} \mathrm{N}\right)$ have been produced by means of this simulator. The total number of pixels processed is nearly 2 million, thus a massive computing grid architecture has been necessary, i.e. the EGI (European Grid Infrastructure)-France Grilles facility (Eremenko et al., 2012).

\subsection{Approximated averaging kernels}

Following Rodgers (2000), it is possible to obtain approximated POs, i.e. without the full RT calculation, by using the Eq. (1)

$\boldsymbol{x}_{\mathrm{PO}}=\mathbf{A}^{\prime} \boldsymbol{x}_{\mathrm{NR}}+\left(\mathbf{I}-\mathbf{A}^{\prime}\right) \boldsymbol{x}_{\mathrm{a}}+\mathbf{G} \boldsymbol{e}$.

In this equation $\boldsymbol{x}_{\mathrm{PO}}$ and $\boldsymbol{x}_{\mathrm{NR}}$ are the pseudo-observation and the NR ozone profiles, $\boldsymbol{x}_{\mathrm{a}}$ is the a priori information, $\mathbf{A}^{\prime}$ is an approximated averaging kernel matrix, $\mathbf{G}$ is the gain matrix, $\boldsymbol{e}$ is the radiometric noise. $\mathbf{A}^{\prime}$ and $\mathbf{G} \boldsymbol{e}$ must reflect the instrument response in terms of the vertical sensitivity and noise. The main idea underlying fast approximated OSSEs is that $\mathbf{A}^{\prime}$ is a reasonable approximation of the full RT AKs, i.e. that $\mathbf{A}^{\prime}$ is sufficient to fully describe the vertical sensitivity of the observing system with respect to the observed quantity. In general, it is expected that the full RT AKs are scene-dependent, i.e. they depend on several parameters of the NR.

We compared our full RT pseudo-observations with two approximations: one based on the use of a single average scene-independent $\mathbf{A}^{\prime}$ over the whole region of study (hereafter referred to as approximation 1), and the other based on the use of a limited scene-dependent set of $\mathbf{A}^{\prime}(\Delta T)$, as a function of the thermal contrast $(\Delta T)$ between the surface and the lowest air layer (hereafter referred to as approximation 2). Approximation 1 and 2 are inspired from the approximations recently used to carry out fast OSSEs aimed at studying the impact on LT ozone monitoring of GEO-CAPE 
(GEOstationary Coastal and Air Pollution Events) (Zoogman et al., 2011) and MAGEAQ (Claeyman et al., 2011a), respectively. The approximation $1 \mathbf{A}^{\prime}$ was obtained by running our pseudo-observations simulator only once over a hypothetical scene with standard summer mid-latitudes climatological vertical profiles of temperature, pressure and trace gases, and a standard surface temperature. The approximation $2 \mathbf{A}^{\prime} \mathrm{s}$ were obtained as a look-up-table of AK matrices, by running our pseudo-observations simulator 201 times, with a set of hypothetical scenes with thermal contrast changing from -20 to $+20 \mathrm{~K}$ with steps of $0.2 \mathrm{~K}$. For both approximations a measurement noise component $\mathbf{G} \boldsymbol{e}$ (random Gaussian noise) has been added to simulate the noise equivalent spectral radiance of $6.04 \mathrm{nW}\left(\mathrm{cm}^{2} \mathrm{srcm}^{-1}\right)^{-1}$, typical of MAGEAQ. For approximation 2, different gain matrices are used, depending on the thermal contrast.

\section{Testing the capability of limited scene-dependent averaging kernels approximations to represent a dedicated observing system for lowermost tropospheric ozone monitoring}

The question addressed by our study is: do the proposed approximated pseudo-observations represent the behaviour of a simulated observing system, when dealing with LT ozone pseudo-observations from a next generation geostationary satellite instrument adapted to air quality monitoring? Here we want to stress that those approximations have been used for similar studies for GEO-CAPE and MAGEAQ. To answer this question, we compare these approximations with a set of corresponding full RT pseudo-observations and with the NR. To test whether or not an approximation is good enough, test criteria must be chosen. The choice of these criteria is problem-dependent and in our case we have chosen two criteria. Criterion 1 tests the capability of the approximations to replicate the variability of AKs, DOF and altitude of maximum sensitivity of the full RT calculations. The DOF is defined as the trace of the AK matrix (Rodgers, 2000) and indicates the number of independent pieces of retrieved profile information. Criterion 1 is tested in Sect. 3.1. Criterion 2 tests the capability to replicate LT ozone spatial patterns and shapes relative to the full RT reference calculations. Criterion 2 is tested in Sect. 3.2.

\subsection{Variability of the averaging kernels and the vertical sensitivity}

We start our study with an analysis of the AKs and sensitivity variability, studying criterion 1 . In particular, we would affirm that the approximated pseudo-observations are a good approximation of the reference full RT pseudo-observations if the variability of their AKs and the distribution of the DOFs and altitude of maximum sensitivity are qualitatively similar.
In Figs. 1 and 2, we show the full RT and approximated integrated AKs for the surface- $6 \mathrm{~km}$ and surface- $3 \mathrm{~km}$ ozone partial columns, respectively. These integrated AKs are obtained by summing up the AKs in the considered height interval, i.e. the integral surface- $6 \mathrm{~km} \mathrm{AK}$ is obtained by summing up the AK matrix rows for nominal altitudes from surface to $6 \mathrm{~km}$ and, analogously, the surface- $3 \mathrm{~km}$ integrated AK sums up the AK matrix rows from surface to $3 \mathrm{~km}$. For these examples, the integrated AKs for all pixels of a whole acquisition (20 August 2009, 09:00 UTC) of MAGEAQ, over Europe, are used. The full RT AKs (Figs. 1a and 2a) can be very variable at the lowest altitudes, which are the most important altitudes for air quality considerations. The proposed approximations cannot properly describe this variability. Even the mean value of the integrated AKs from full RT and approximations can be very different in our case, even if, for approximation 1, it depends on the choice of the single AK used. The mean value of the integrated AKs from surface to $6 \mathrm{~km}$, for the full RT and approximation 1 and 2, is +0.72 , +0.87 (about $21 \%$ overestimation) and +0.90 (about $25 \%$ overestimation), at $1 \mathrm{~km}$, and $-0.20,+0.35$ (about $250 \%$ overestimation) and +0.38 (about $290 \%$ overestimation), at surface. The overestimations are of a similar magnitude for the surface- $3 \mathrm{~km}$ column. The approximations substantially overestimate, on average, the sensitivity to the lowest levels, which are the most important to monitor air quality. Simulations performed with those approximations (no or limited scene-dependence of the AKs) will likely fail in describing the sensitivity of the instrument, e.g. MAGEAQ, to the lowest altitudes.

We next study the spatial distributions of scalar parameters derived from the averaging kernel matrices, which can be used to describe the vertical sensitivity of the POs. To this end, we use the DOFs and the altitude of the maximum sensitivity for the surface- $6 \mathrm{~km}$ and surface- $3 \mathrm{~km}$ ozone columns. The DOF is a quantity that indicates the number of independent pieces of information that can be determined from a measurement. It is linked to the AK matrix by means of the following relationship (Rodgers, 2000)

$\mathrm{DOF}=\operatorname{tr}(\mathbf{A})$.

DOFs for ozone partial columns are obtained from the AK matrix for the ozone profile retrievals by calculating the partial trace, up to the top height of the column. The total DOF or the DOF for the partial columns can be seen as one scalar quantity which describes the more complex AK matrix quantity in terms of the vertical sensitivity of the retrieval. Figures 3 and 4 show the distribution over Europe of the DOF surface- $6 \mathrm{~km}$ and surface- $3 \mathrm{~km}$ for the full RT and approximated pseudo-observations, for a test acquisition of the MAGEAQ (20 August 2009, 09:00 UTC). In addition, Table 1 reports the standard deviation, and the maximum and the minimum values for the DOF surface- $6 \mathrm{~km}$ and surface- $3 \mathrm{~km}$ for the full RT and the approximated POs. The full RT DOFs are much more variable than the DOFs of the 
Table 1. Standard deviation, and maximum and minimum values for the DOF surface- $6 \mathrm{~km}$ and surface- $3 \mathrm{~km}$, for full RT and approximated POs, for the 20 August 2009, 09:00 UTC.

\begin{tabular}{lcccccccc}
\hline & \multicolumn{3}{c}{ DOF surface-6 km } & & \multicolumn{3}{c}{ DOF surface-3 km } \\
\cline { 2 - 3 } \cline { 8 - 9 } & Full RT & Appr. 1 & Appr. 2 & & Full RT & Appr. 1 & Appr. 2 \\
\hline Standard deviation & 0.31 & 0.04 & 0.06 & & 0.32 & 0.05 & 0.07 \\
Minimum value & 0.65 & 0.74 & 0.73 & & 0.22 & 0.41 & 0.39 \\
Maximum value & 1.46 & 1.09 & 1.21 & & 0.83 & 0.57 & 0.68 \\
\hline
\end{tabular}
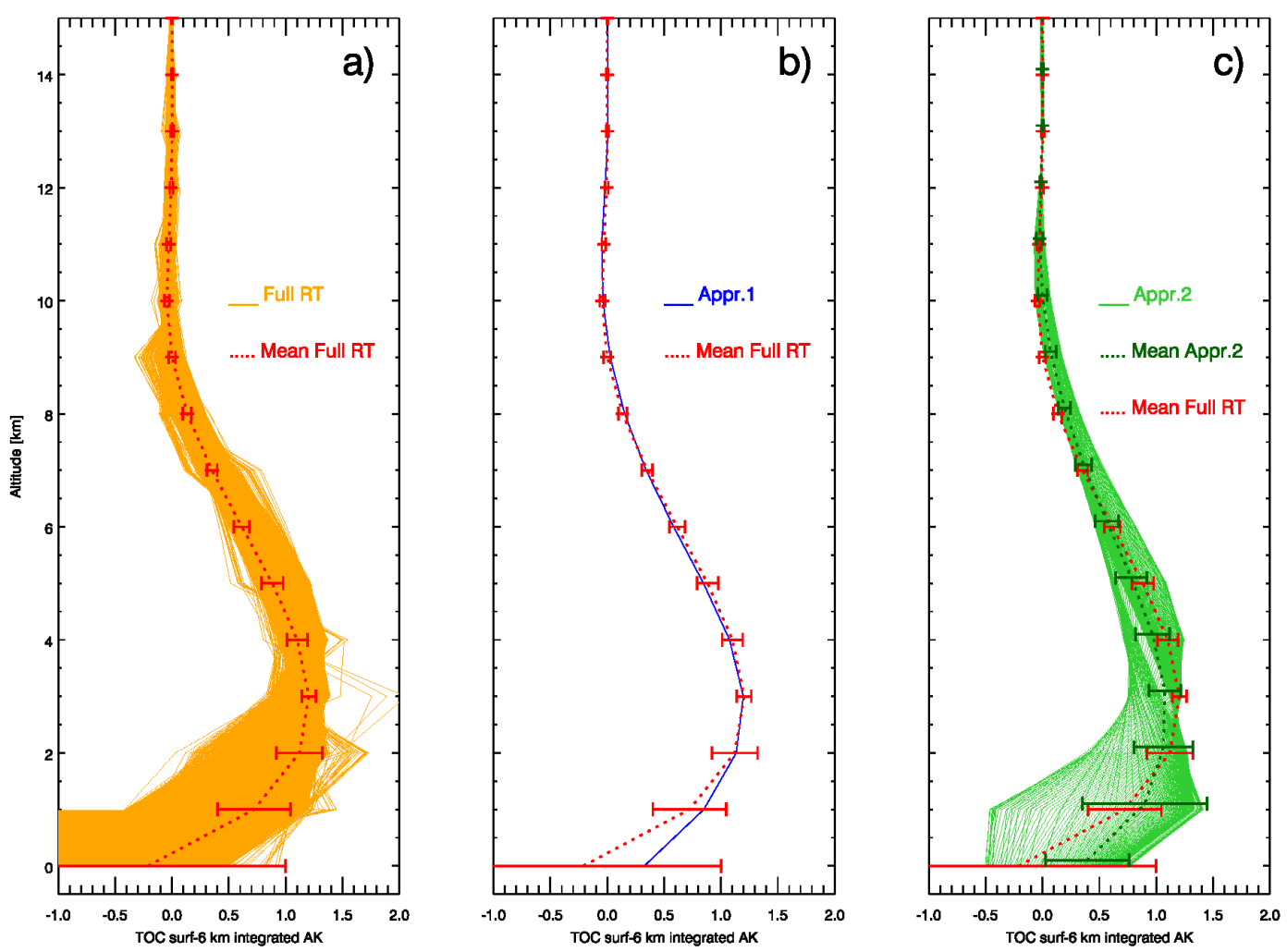

Fig. 1. Full RT (a, in orange), approximation 1 (b, in blue) and approximation 2 (c, in light green) integral averaging kernels for the ozone partial column from surface to $6 \mathrm{~km}$, for 20 August 2009 09:00 UTC, over Europe. The mean averaging kernel and standard deviation (points and bars) for full RT is also shown (red line), as well as for approximation 2 (green line).

approximated POs. Apart from trivial considerations on the DOF of approximation 1, a single constant value, only modulated by the topography, now we concentrate on the comparison of the full RT and approximation 2 DOFs. The hypothesis of approximation 2 is that the sensitivity of a thermal infrared observation of ozone is mainly dependent on the thermal contrast between surface and the first air layer. The DOFs surface- $6 \mathrm{~km}$ and surface- $3 \mathrm{~km}$ for approximation 2 , in Figs. 3 and 4, reasonably follow the thermal contrast spatial distribution, with, for example, higher values over land than over oceans. This behaviour is only partially verified by the reference full RT pseudo-observations. In fact, while there are regions where the land-sea differences are dominant, e.g. in the Mediterranean region, some areas with other spatial distributions can be identified. The most relevant difference is found in the North-West quadrant. There, we see a strong gradient of the DOFs in the East-West direction, with a maximum over the Atlantic Ocean (about 1.3 and 0.7, for the surface- $6 \mathrm{~km}$ and surface- $3 \mathrm{~km}$ columns) and a minimum over the North Sea, between the UK and Scandinavia (about 1.0 and 0.3 , for the surface- $6 \mathrm{~km}$ and surface- $3 \mathrm{~km}$ columns). This behaviour is not related to thermal contrast distributions, thus is not properly described by approximation 2 (more details are provided in the next paragraph). To quantify the differences between full RT and the approximations, we consider the values in the low sensitivity region over the North Sea. There, the full RT DOFs surface- $6 \mathrm{~km}$ are about 0.86 on average, while for the two approximations they 

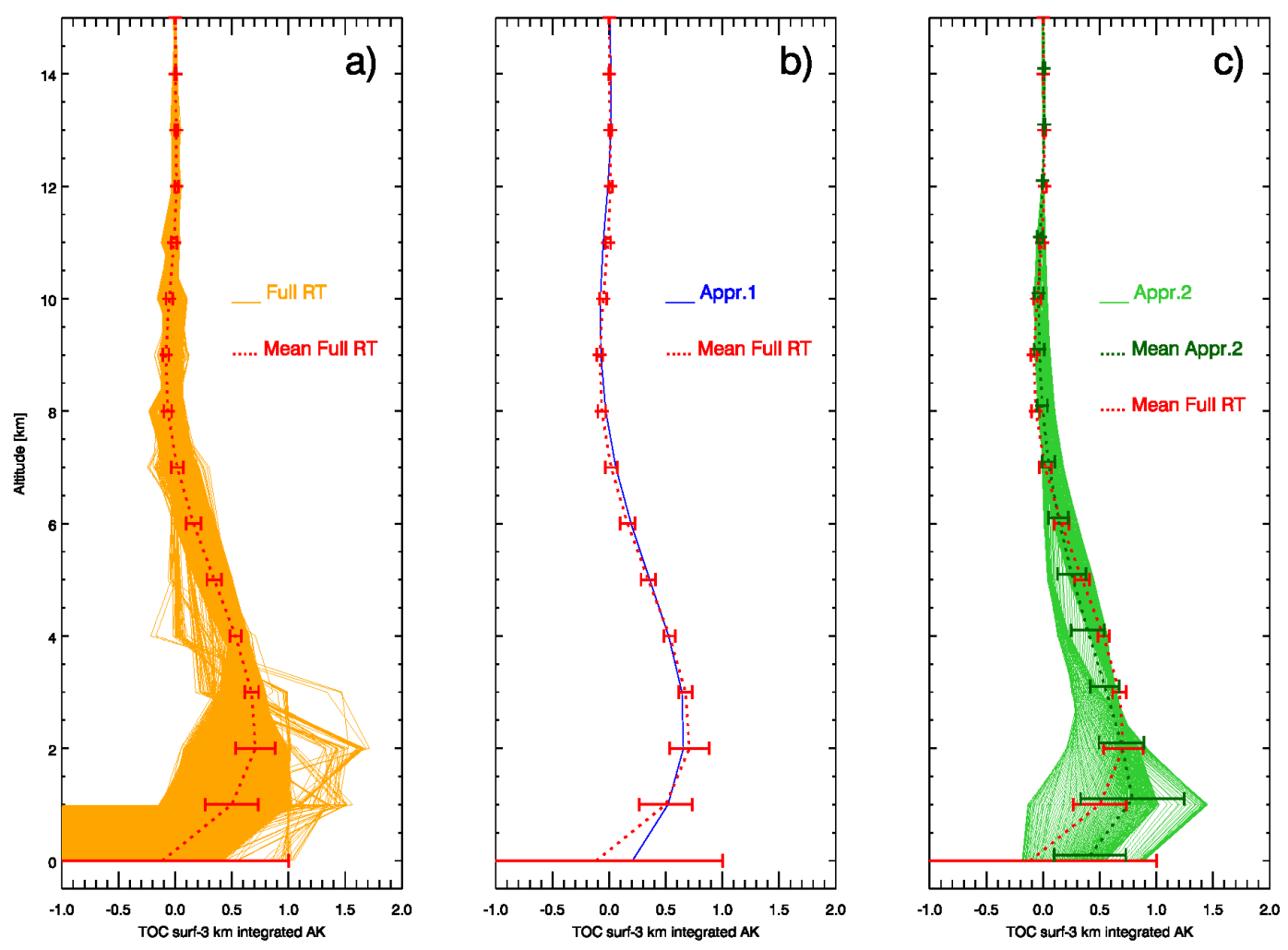

Fig. 2. Same as Fig. 1 but for the the ozone partial column from surface to $3 \mathrm{~km}$.

are about $1.12(+30.2 \%)$ and $1.02(+18.6 \%)$ and, for the DOFs surface- $3 \mathrm{~km}$, we have $0.30,0.61(+103.3 \%)$ and 0.52 $(+73.3 \%)$, so leading to a strong overestimation of the sensitivity for the approximated POs.

We further investigate some of the NR variables that affect the spatial distribution of the DOFs shown in Figs. 3 and 4. By means of a multiple correlation analysis, we have found that the variability of the DOF surface- $3 \mathrm{~km}$ and surface- $6 \mathrm{~km}$ can be more strongly correlated with the tropopause height, the vertical temperature profile and the LT ozone columns than the thermal contrast, in some areas and at some time of observation. As an example, in Fig. 5 we show the patterns of the DOF surface- $6 \mathrm{~km}$ for the 20 August, 09:00 UTC (already shown in Fig. 3), and we compare them with the coincident spatial distributions of the tropopause height and the thermal contrast. There are large regions where the DOF structures follow the tropopause height patterns, e.g. in the North-West quadrant. In that area, low tropopauses are generally related to high values of the DOFs. The correlation coefficient in that area $\left(15^{\circ} \mathrm{W}-20^{\circ} \mathrm{E}, 50^{\circ} \mathrm{N}-65^{\circ} \mathrm{N}\right)$ reaches a value as high as -0.81 , for the comparison DOF surface- $6 \mathrm{~km} /$ tropopause height, while it is 0.20 for the comparison DOF surface$6 \mathrm{~km} /$ thermal contrast. Figure 5 also shows the AK for the ozone column from surface to $6 \mathrm{~km}$, for two pixels on the mentioned line of strong DOF gradient in the East-West direction, between the Atlantic Ocean and the North Sea (see discussion in the previous paragraph), location 1: $\left(55.44^{\circ} \mathrm{N}\right.$, $\left.12.53^{\circ} \mathrm{W}\right)$ and location $2:\left(55.72^{\circ} \mathrm{N}, 5.33^{\circ} \mathrm{E}\right)$. The two locations have roughly the same thermal contrast, 0.2 and $0.3 \mathrm{~K}$, respectively. On the contrary, the tropopause height (and the temperature profile) is very different, 9 and $13 \mathrm{~km}$, respectively. The AKs and the DOFs for the two locations are very different. The DOFs are 1.25 and 0.89 , for the two pixels. The differences in the shape of the AK and the DOF values are then not related to differences in the thermal contrast. The influence of the thermal contrast, however, is dominant for the determination of the differences oceans/land in the southern section, with simultaneous higher values of the thermal contrast and DOF on the land, see, e.g. over Italy, France and the general behaviour over the Mediterranean basin. This further indicates that different parameters, the tropopause height in our example, can affect the AK shape of such geostationary thermal infrared measurements, and then the sensitivity to the target LT ozone concentrations.

Another important parameter to describe the sensitivity of the observations is the altitude of the maximum of the integrated AK for a fixed ozone column. This quantity indicates from which altitude the maximum of the information on the ozone column retrieval comes. Figures 6 and 7 show the distribution over Europe of the altitude of maximum sensitivity of the ozone partial columns from surface to $6 \mathrm{~km}$ and from surface to $3 \mathrm{~km}$ for the full RT and approximated 
Full RT

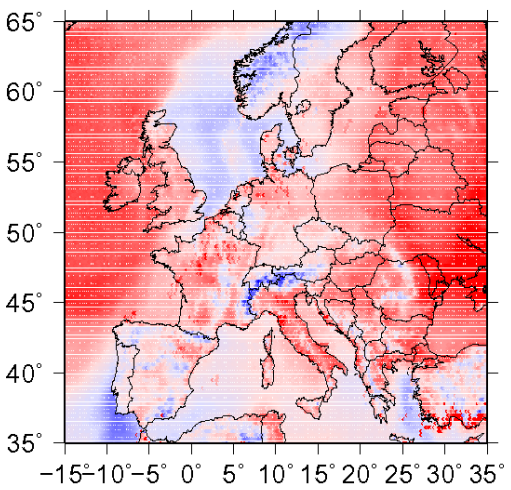

Approximation 1

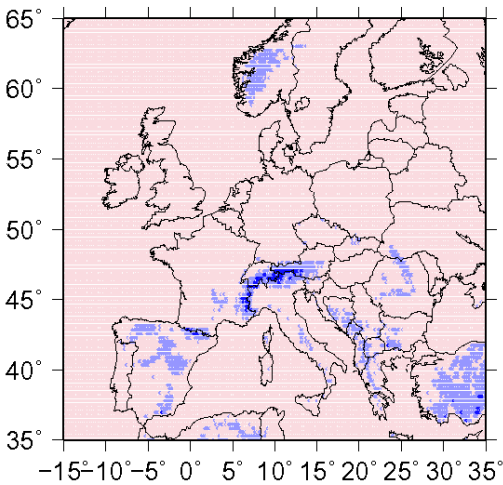

Approximation 2

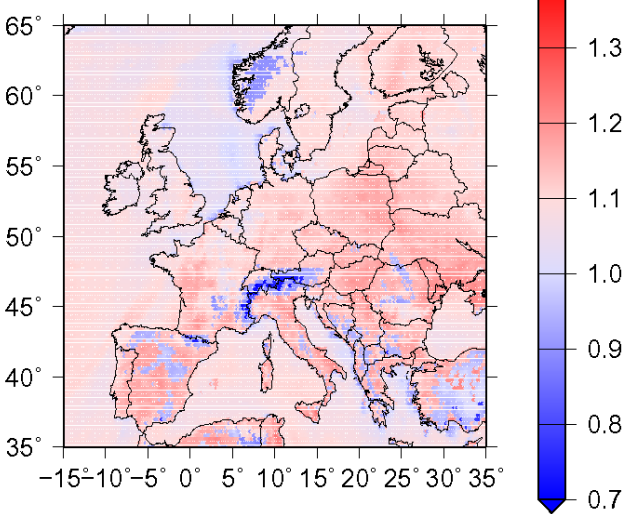

Fig. 3. Distribution over Europe of the DOFs surface- $6 \mathrm{~km}$ for full RT (left panel), approximation 1 (central panel) and 2 (right panel), for the 20 August 2009, 09:00 UTC.

Full RT

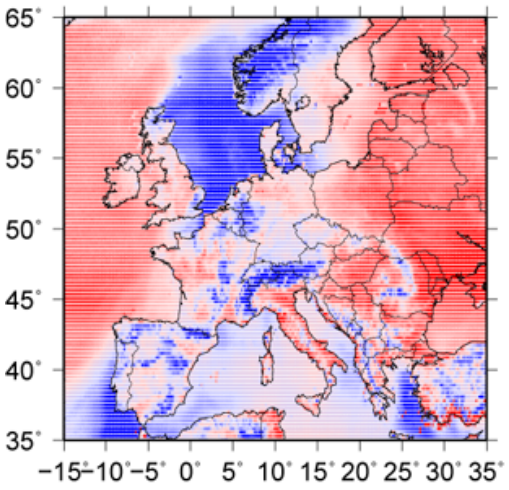

Approximation 1

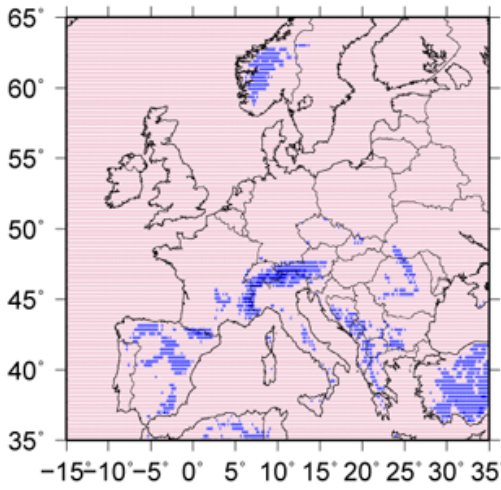

Approximation 2

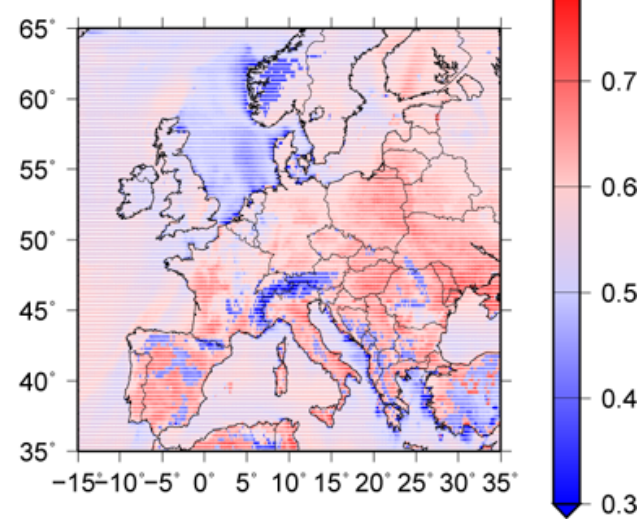

Fig. 4. Same as Fig. 3 but for the DOFs surface- $3 \mathrm{~km}$.

pseudo-observations, for the same test acquisition of Figs. 3 and 4. The issues identified above for the DOFs are confirmed for the altitude of maximum sensitivity. For example, the sensitivity of the surface- $6 \mathrm{~km}$ and surface- $3 \mathrm{~km}$ columns over the North Sea, between the UK and Norway (the area of marked differences between full RT and approximated DOFs) peaks at $4 \mathrm{~km}$ on average for the full RT and at altitudes lower of 1 to $2 \mathrm{~km}$ for the approximations. The approximations are not good enough to replicate the complexity of the sensitivity to lower tropospheric ozone of MAGEAQ, also over other areas (e.g. the Iberian peninsula or Turkey). The marked differences of full RT and approximation 2 altitudes of maximum sensitivity are a further indication that a limited scene-dependent characterisation of the sensitivity of an instrument may produce unrepresentative POs.
For this example, the results of Figs. 1 and 2 are confirmed by the analysis of the spatial distribution of the DOFs and altitudes of maximum sensitivity of the surface- $6 \mathrm{~km}$ and surface- $3 \mathrm{~km}$ ozone columns. These quantities, computed with a complete RT calculation, show a very complex spatial variability. This variability cannot be described by approximation 1 . In addition, the patterns of DOF and altitude of maximum sensitivity are not simply and exclusively linked to variations in thermal contrast, and so also approximation 2 is inadequate. In general, we found that these two approximations are not sufficiently complex, in terms of the dependency on NR's parameters to describe the vertical sensitivity of pseudo-MAGEAQ measurements over Europe for this test acquisition (20 August 2009, 09:00 UTC). From the point of view of criterion 1 , we can affirm that the test approximations, with no, or limited, scene-dependence, are not 

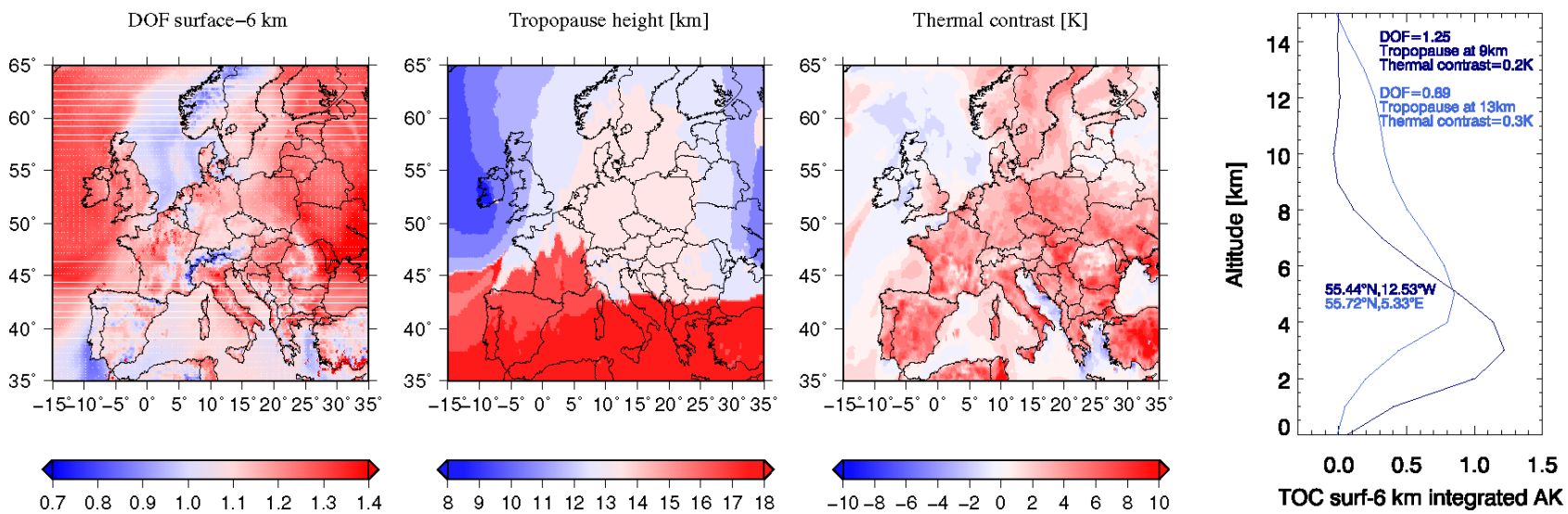

Fig. 5. Distribution over Europe of the full RT DOFs surface- $6 \mathrm{~km}$ for full RT (left panel), and tropopause height (centre-left panel) and thermal contrast (centre-right panel) from MOCAGE NR, for the 20 August 2009, 09:00 UTC. The surface-6 km ozone column integrated AKs, for two selected locations, are also shown (right panel).

Full RT

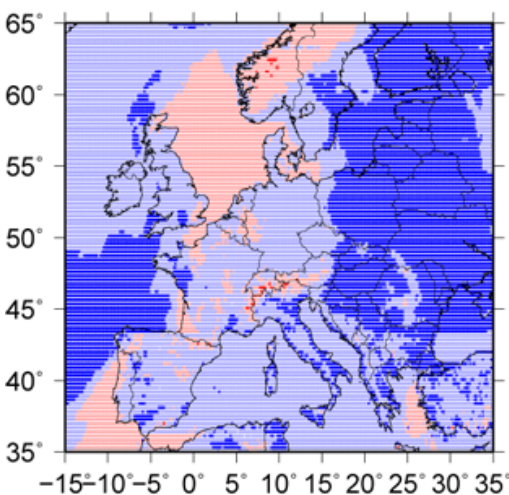

Approximation 1

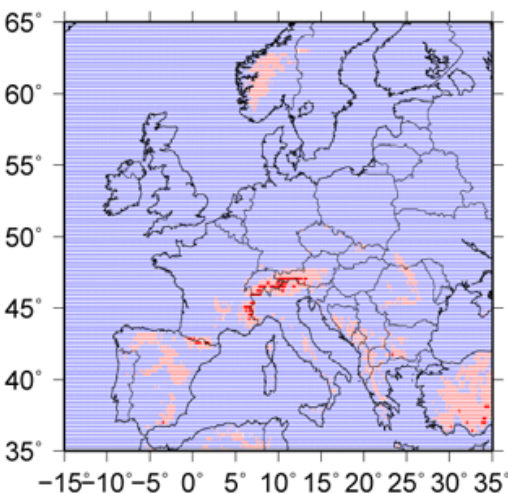

Approximation 2

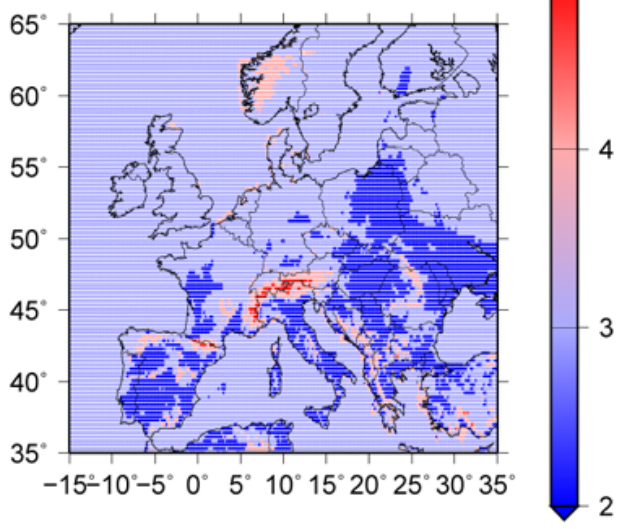

$\mathrm{km}$

Fig. 6. Distribution over Europe of the altitude of maximum sensitivity of surface- $6 \mathrm{~km}$ ozone columns for full RT (left panel), approximation 1 (central panel) and 2 (right panel), for the 20 August 2009, 09:00 UTC.

good approximations of the observing system response. This lack of representativeness of the approximations 1 and 2 is expected to affect the capability of the approximated pseudoobservations to properly describe the target observing system and its capability to follow lower tropospheric ozone plumes evolutions. This effect, which involves criterion 2 is studied in the next section.

\subsection{Lower tropospheric ozone distributions during the pollution event of 19-21 August 2009}

We now consider the distributions of the ozone partial column from surface to $6 \mathrm{~km}$ over Europe and the time series over selected locations, for the test case of the ozone plume evolution for the period 19-21 August 2009. This pollution event was used as a case-study also by Sellitto et al. (2013). During these three days, significantly higher values of the lower tropospheric ozone column, that formed over France (19 August), moved northwards and eastwards during the subsequent days, reaching Germany, Poland and Sweden (20-21 August). The plume crosses the North Sea on $20 \mathrm{Au}-$ gust, touching the area with limited measurement sensitivity, described in Sect. 3.1. We try to understand if the spatial and temporal description of this ozone plume evolution is reasonably approximated by approximations 1 and 2 .

Figure 8 shows maps of the NR, full RT and approximated MAGEAQ POs of surface- $6 \mathrm{~km}$ ozone partial columns, for the day 20 August 2009 at 09:00 UTC, when the ozone plume reached the North Sea area with a major difference on the expected sensitivity from full RT and approximated AKs (see 
Full RT

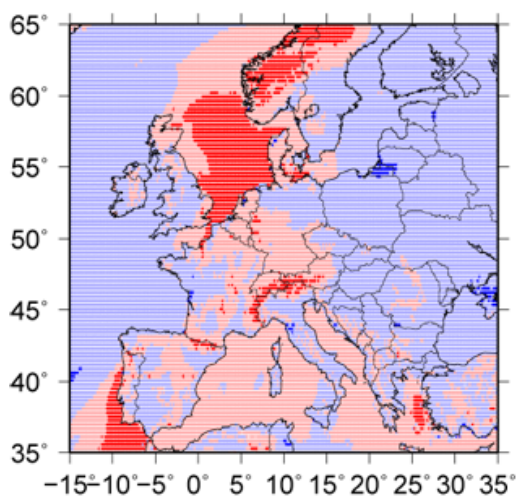

Approximation 1

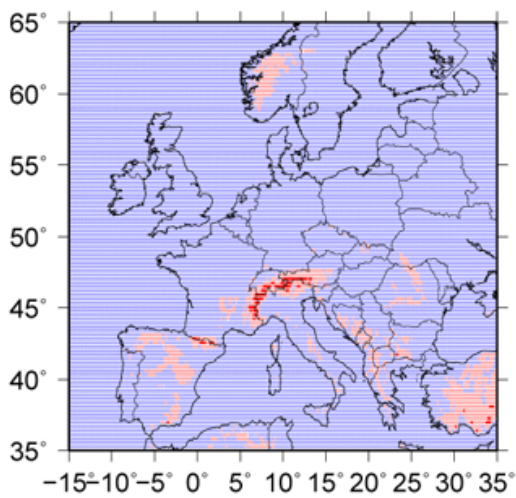

Approximation 2

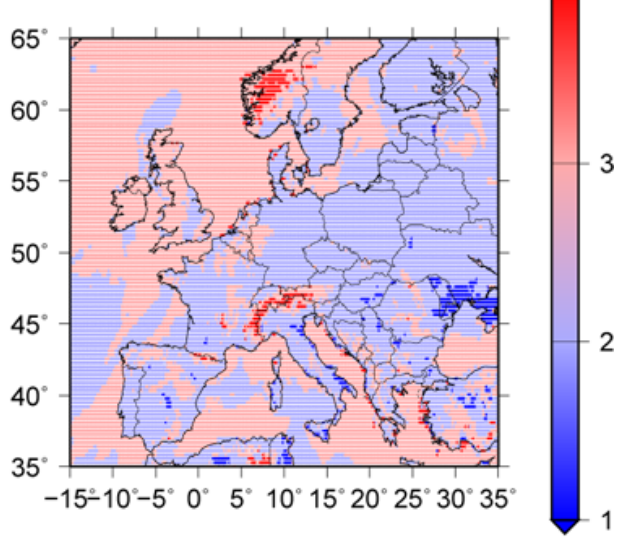

$\mathrm{km}$

Fig. 7. Same as Fig. 6 but for the surface- $3 \mathrm{~km}$ ozone columns.

MOCAGE NR
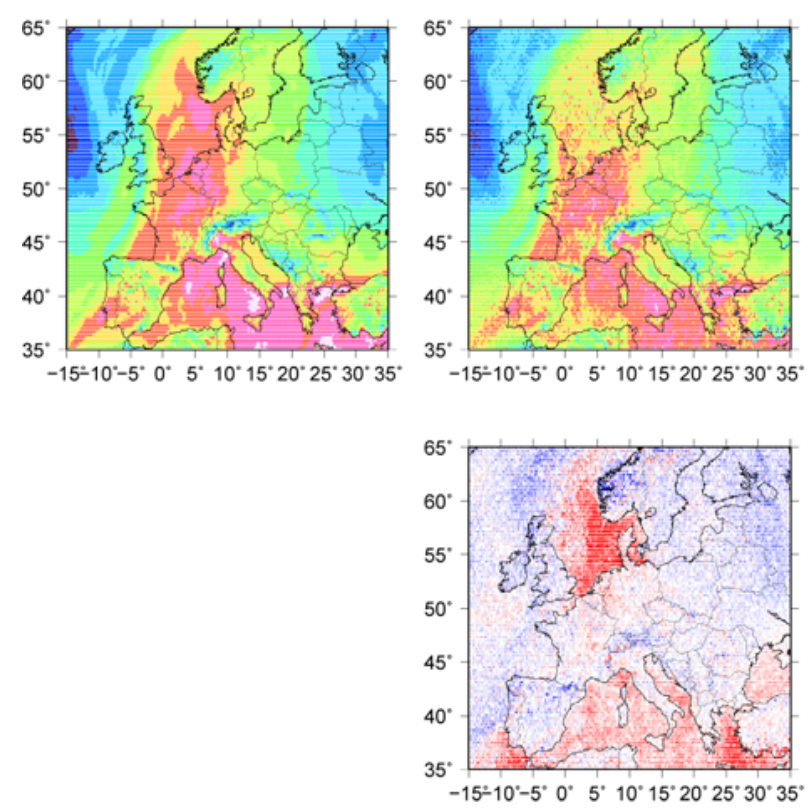

Full RT
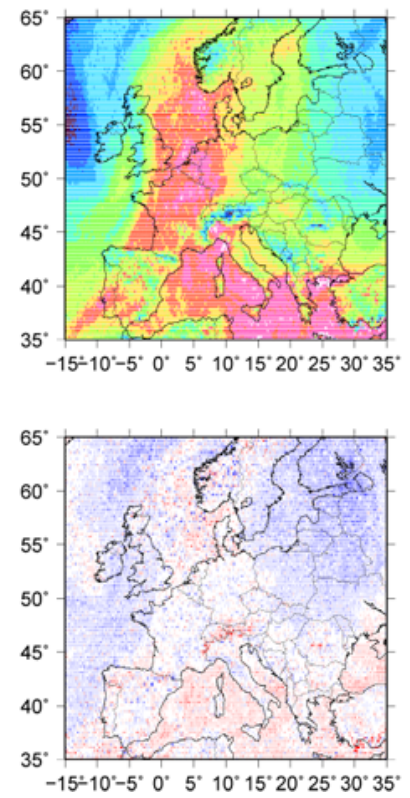

Approximation 1
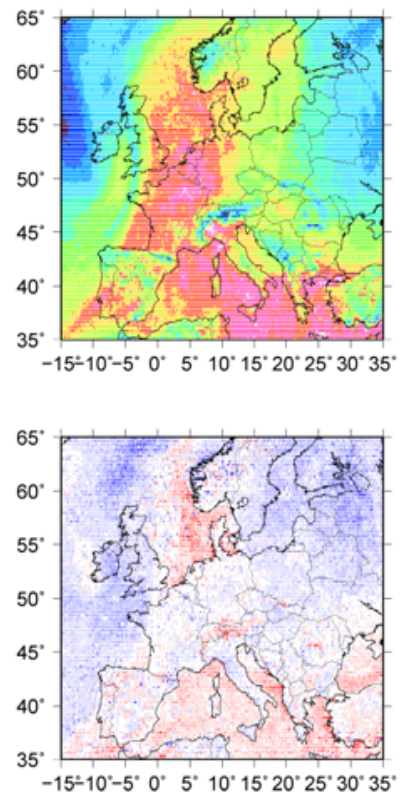
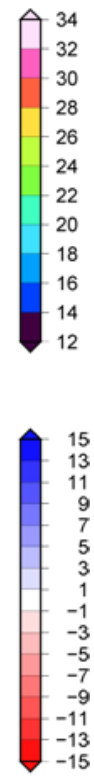

Fig. 8. Surface-6 km ozone partial column over Europe, 20 August 2009 at 09:00 UTC, from MOCAGE NR (left panels), full RT pseudoobservation (centre-left panels) and approximated pseudo-observations (centre-right and right panel panels) (top panels); percent differences of full RT and approximated pseudo-observations with respect to MOCAGE NR (bottom panels).

Figs. 3-7). The first evidence is that the full RT MAGEAQ POs do not observe a contiguous plume and they see significantly smaller values over the North Sea. The values in the ozone plume region crossing the North Sea are very similar (25.6 DU in the rectangle $54^{\circ} / 60^{\circ} \mathrm{N}-0 / 10^{\circ} \mathrm{E}$ ) to the background values of the surrounding area (about $24 \mathrm{DU}$ ). Taking account of AK scene-dependent variability, this suggests that MAGEAQ, in the framework of a complete RT characterisation, may be not sufficiently sensitive, in that situation, to completely discriminate this ozone plume and its shape. The situation is very different for the two approximated POs datasets. For both approximated POs, a contiguous lower tropospheric ozone plume is observed, with average values, over the ozone plume region crossing the North Sea (approximation 1: 29.2 DU, approximation 2: $28.5 \mathrm{DU}$, in the rectangle $54^{\circ} / 60^{\circ} \mathrm{N}-0 / 10^{\circ} \mathrm{E}$ ), very different from the 
background values in the surrounding area, and very different from the full RT characterisation. The approximated POs are very similar to NR lower tropospheric ozone patterns (see map on the left of Fig. 8). In Fig. 8 we also show the percent differences of full RT and approximated POs with respect to the NR (bottom line). The marked underestimation of the full RT MAGEAQ POs is here more clearly shown. Over the North Sea, we found an average $-14.8 \%$ differences, with respect to NR. On the contrary, the approximated POs overestimate the resolving capability of MAGEAQ over the same region $(-0.3$ and $-4.5 \%$ differences, on average, with respect to NR). The estimated mean total retrieval error in that region is $7.4 \%$, so the underestimation for full RT POs is significant.

We introduce the parameter $D$ to quantitatively characterise the concurrent distance between POs and NR. $D$ measures the ratio of the Euclidean distances of the approximated lower tropospheric ozone partial column (TOC, in the equation) PO and the NR, and approximated and full RT POs, see Eq. (3)

$D=\lg \frac{\left|\mathrm{TOC}_{\mathrm{Appr}}-\mathrm{TOC}_{\mathrm{NR}}\right|}{\left|\mathrm{TOC}_{\mathrm{Appr}}-\mathrm{TOC}_{\mathrm{FullRT}}\right|}$.

Values of $D>0(<0)$ are linked with approximated POs closer to full RT POs than to NR (and viceversa). The more pixels with $D>0$, the better the approximations are. Figure 9 shows the histogram of the values of $D$ for all the pixels of the 20 August 2009 at 09:00 UTC, for the two approximations (approximation 1: solid line; approximation 2: dotted line), for the surface- $6 \mathrm{~km}$ column. We found that the most of the approximated lower tropospheric ozone POs are closer to the NR than the full RT POs (about 59 and $54 \%$, for the approximation 1 and 2, respectively). In practice, the approximated POs description of the observing system is closer to the NR than to the target POs. We have found a similar behaviour of the approximated POs for the whole three days period of the present study. However, we wish to stress that this is not a general result. While we observe that the performances of approximation 1 are generally similar over different NR's configurations, we have found better performances of the approximation 2 in cases where the NR is not characterised by ozone plume evolutions. For example, the number of pixels with $D<0$, for the 1 August 2009, 09:00 UTC, is about $51 \%$ for approximation 1 and about $22 \%$ for approximation 2 .

Finally, we investigate the temporal evolution of the POs over selected locations. Figure 10 shows the time series, for the period 19-21 August 2009, of the ozone partial columns POs and NR at two close locations. The first is a marine location on the North Sea $\left(58.1^{\circ} \mathrm{N}-4.2^{\circ} \mathrm{W}\right)$ and the second is the city of Amsterdam. The two locations are affected by the ozone plume at roughly the same time, on 20 August 2009. Figure 10 also shows the time series of the differences of approximated and full RT POs with respect to NR. The analysis

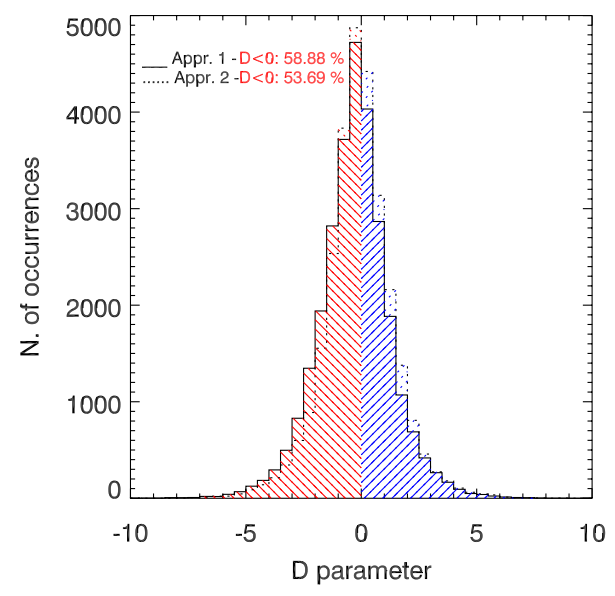

Fig. 9. Histogram of the parameter $D$ (see Eq. 3) for all pixels over Europe for the day 20 August 2009, 09:00 UTC, for the surface$6 \mathrm{~km}$ ozone partial column.

of the time series of the POs over these two locations shows that, the approximations may sometimes work well, e.g. Amsterdam (differences with respect to NR $<10 \%$ for both approximated and full RT POs). However, they can also be completely misrepresentative of the full RT, see, for example, the location over the North Sea, where the full RT underestimation of up to $30 \%$ of the partial column are not well described by approximated PO. The maximum differences are on the 20 August morning, at the passage of the ozone plume. This discussion also demonstrates that the accuracy of the approximations considered here strongly depends on the region analysed.

The study described in this section was aimed to the demonstration that these two approximations are not sufficiently complex to describe how the MAGEAQ would be able to observe the evolution of the LT ozone plume of the 19-21 August 2009. So, also from the point of view of criterion 2, we can affirm that the test approximations, with no or limited scene-dependence, are not a good approximations of the observing system response.

\section{Conclusions}

In this paper, we have presented a comparison of lower tropospheric ozone synthetic observations obtained with full RT calculations and with approximated schemes based on prior assumptions about the AKs. We have simulated three days (19-21 August 2009) of synthetic observations, over Europe, from the concept geostationary instrument MAGEAQ. The approximated POs have been obtained with assumption of no, or limited, dependency of the AKs from the scene defined by the NR. These assumptions have been recently used for OSSEs aimed to assess the capability of future geostationary instruments (GEO-CAPE and MAGEAQ) to monitor LT ozone. To verify the two approximations, we have chosen 

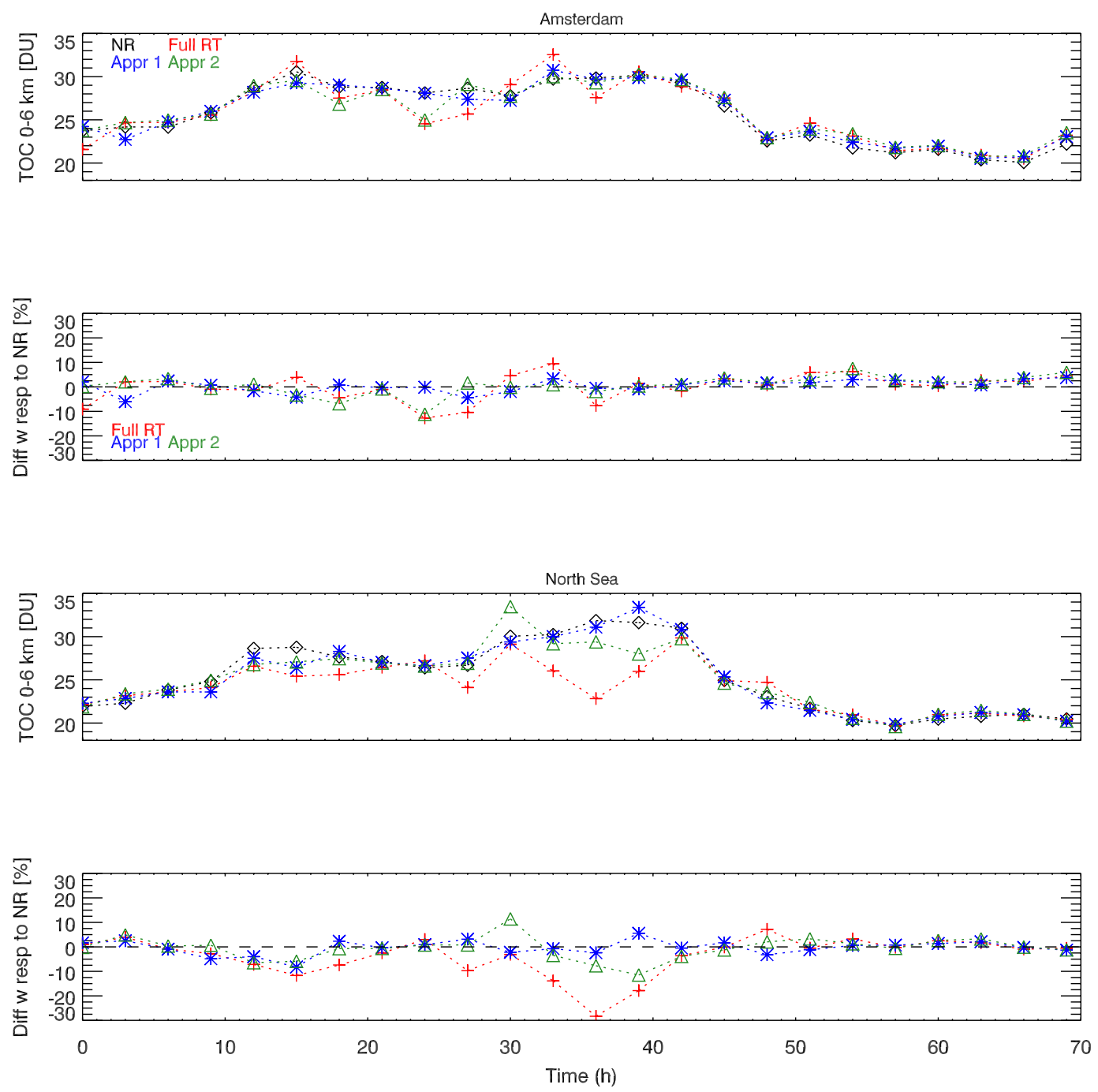

Fig. 10. Time series (19-21 August 2009, 3 h sampling) of surface-6 km ozone partial column from MOCAGE NR (black), and full RT (red) and approximated MAGEAQ POs (approximation 1: blue, approximation 2: green), over Amsterdam, the Netherlands, and one marine location west of Southern Norway coast $\left(58.1^{\circ} \mathrm{N}-4.2^{\circ} \mathrm{W}\right)$. Time series of the differences of POs with respect to NR are also provided.

two test criteria: we test the capability of the approximated POs to replicate the variability of the AKs and the distribution of the DOFs and altitude of maximum sensitivity (criterion 1), and to emulate the LT ozone spatial patterns (criterion 2) of the full RT retrievals.

As for test criterion 1, we have found that none of the approximations are able to describe the AK variability for the surface- $6 \mathrm{~km}$ and surface- $3 \mathrm{~km}$ columns, especially at the lowest altitudes. We observe a general overestimation of the AK values at the lowest levels. We have also found that the approximated POs are not able to properly describe the small scale variability in the sensitivity of the full RT POs, in terms of the DOFs and altitude of maximum sensitivity. The most relevant case is a strong gradient of these two quantities, following the East-West direction in the North-West quadrant (approximately between the Atlantic Ocean, west of Ireland, and the North Sea, between UK and Scandinavia), which is not replicated by the approximations. As for test criterion 2, we studied the evolution of a LT ozone plume, developing between 19 and 21 August 2009, and affecting the region between Southern France and the Scandinavian peninsula, on different days. The most important feature is the overoptimistic description of this ozone pollution phenomenon done by the two approximated POs datasets. The plume is not detected by the full RT POs, while the approximations see a contiguous and resolved plume. This effect is strongly related to the overestimated sensitivity, found by test criterion 1, over the North Sea area affected by the ozone plume crossing on the 20 August. This behaviour is confirmed by the analysis of the time series of the full RT and approximated POs in that area. We have also shown that, in cases like the 20 August, 
the description of the approximated POs is closer to the NR than to the full RT POs.

Based on the two test criteria, we finally affirm that the proposed approximations of AKs (with no, or limited, scene-dependence) are not sufficiently complex to emulate/substitute a full RT PO simulator to evaluate the expected capability of the MAGEAQ (or similar observing systems) to monitor the short term/small scale evolution of lower tropospheric ozone during a typical pollution event. More complex scene-dependent parametrizations of the AKs, e.g. by considering a larger number of scene parameters corresponding to real satellite observations (including height-dependent parameters, e.g. temperature or active trace gases profiles) is planned (Worden et al., 2013). In fact, doing fast OSSEs remains important due to the very important computation requirements when dealing with longer periods of time and/or larger dimensionality of the problem (e.g. multi-spectral observing systems or multi-instruments studies). Making detailed RT calculations, in these cases, is not always feasible and an effective and sufficiently complex scene-dependent AK parametrization is highly desirable.
Acknowledgements. The authors are grateful to CNRS-INSU for publication support. This work is carried on in the framework of the CNES/TOSCA/GeoQAir (quantification de l'apport d'une plateforme d'observations GÉOstationnaires pour la surveillance de la Qualité de l'AIR). We wish to thank the Institut für Meteorologie und Klimaforschung (IMK), Karlsruhe Institute of Technology (KIT), Germany, for a licence to use KOPRA radiative transfer model. The authors acknowledge the use of resources provided by the European Grid Infrastructure. For more information, please reference the EGI-InSPIRE paper (http://go.egi.eu/pdnon). MOCAGE data have been provided by Météo France. We wish to thank Helen Worden for fruitful discussions and helpful comments. The associate editor Patrick Eriksson and the two anonymous referees are gratefully acknowledged for the constructive criticism that helped improving the quality of the paper.

Edited by: P. Eriksson

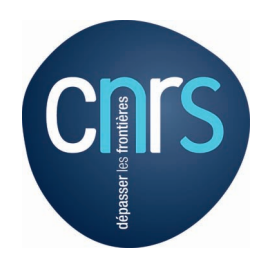

The publication of this article is financed by CNRS-INSU.

\section{Appendix A}

\section{List of abbreviations}

\begin{tabular}{|c|c|}
\hline AK & Averaging Kernels \\
\hline AR & Assimilation Run \\
\hline $\mathrm{CR}$ & Control Run \\
\hline DOF & Degrees Of Freedom \\
\hline EGI & European Grid Infrastructure \\
\hline GEO-CAPE & $\begin{array}{l}\text { GEOstationary Coastal and } \\
\text { Air Pollution Events }\end{array}$ \\
\hline IASI & $\begin{array}{l}\text { Infrared Atmospheric Sounding } \\
\text { Interferometer }\end{array}$ \\
\hline KOPRA & $\begin{array}{l}\text { Karlsruhe Optimized and Precise } \\
\text { Radiative transfer Algorithm }\end{array}$ \\
\hline LT & Lower Troposphere \\
\hline MAGEAQ & $\begin{array}{l}\text { Monitoring the Atmosphere from } \\
\text { Geostationary orbit for European } \\
\text { Air Quality }\end{array}$ \\
\hline MOCAGE & $\begin{array}{l}\text { MOdèle de Chimie Atmosphérique } \\
\text { à Grande Echelle }\end{array}$ \\
\hline NR & Nature Run \\
\hline OSSE & $\begin{array}{l}\text { Observing System Simulation } \\
\text { Experiment }\end{array}$ \\
\hline $\mathrm{PO}$ & Pseudo-Observation \\
\hline RT & Radiative Transfer \\
\hline TOC & Tropospheric Ozone Column \\
\hline ROI & Region Of Interest \\
\hline
\end{tabular}

\section{References}

Amann, M., Bertok, I., Cofala, J., Gyarfas, F., Heyes, C., Klimont, Z., Schöpp, W., and Winiwarter, W.: Baseline scenarios for the Clean Air For Europe (CAFE) programme, Tech. rep., International Institute for Applied Systems Analysis, for the European Commission Directorate General for Environment, Directorate C: Environment and Health, Laxenburg, Austria, 2005.

Arnold, C. P. and Clifford, H. D.: Observing-systems simulation experiments: past, present, and future, B. Am. Meteorol. Soc., 67, 687-695, 1986.

Claeyman, M., Attié, J.-L., Peuch, V.-H., El Amraoui, L., Lahoz, W. A., Josse, B., Joly, M., Barré, J., Ricaud, P., Massart, S., Piacentini, A., von Clarmann, T., Höpfner, M., Orphal, J., Flaud, J.M., and Edwards, D. P.: A thermal infrared instrument onboard a geostationary platform for $\mathrm{CO}$ and $\mathrm{O}_{3}$ measurements in the lowermost troposphere: Observing System Simulation Experiments (OSSE), Atmos. Meas. Tech., 4, 1637-1661, doi:10.5194/amt-41637-2011, 2011a.

Claeyman, M., Attié, J.-L., Peuch, V.-H., El Amraoui, L., Lahoz, W. A., Josse, B., Ricaud, P., von Clarmann, T., Höpfner, M., Orphal, J., Flaud, J.-M., Edwards, D. P., Chance, K., Liu, X., Pasternak, F., and Cantié, R.: A geostationary thermal infrared sensor to monitor the lowermost troposphere: $\mathrm{O}_{3}$ and $\mathrm{CO}$ retrieval studies, Atmos. Meas. Tech., 4, 297-317, doi:10.5194/amt-4-297-2011, $2011 b$.

Dufour, A., Amodei, M., Ancellet, G., and Peuch, V.-H.: Observed and modelled chemical weather during ESCOMPTE, Atmos. Res., 74, 161-189, doi:10.1016/j.atmosres.2004.04.013, 2005.

Dufour, G., Eremenko, M., Griesfeller, A., Barret, B., LeFlochmoën, E., Clerbaux, C., Hadji-Lazaro, J., Coheur, P.-F., and Hurtmans, D.: Validation of three different scientific ozone products retrieved from IASI spectra using ozonesondes, 
Atmos. Meas. Tech., 5, 611-630, doi:10.5194/amt-5-611-2012, 2012.

Edwards, D. P., Arellano Jr., A. F., and Deeter, M. N.: A satellite observation system simulation experiment for carbon monoxide in the lowermost troposphere, J. Geophys. Res., 114, D14304, doi:10.1029/2008JD011375, 2009.

Eremenko, M., Dufour, G., Foret, G., Keim, C., Orphal, J., Beekmann, M., Bergametti, G., and Flaud, J.-M.: Tropospheric ozone distributions over Europe during the heat wave in July 2007 observed from infrared nadir spectra recorded by IASI, Geophys. Res. Lett., 35, L18805, doi:10.1029/2008GL034803, 2008.

Eremenko, M., Weissenbach, D., Sellitto, P., Cuesta, J., Forêt, G., and Dufour, G.: GeoQAIR : quantification de l'apport d'une plateforme satellitaire d'observations Géostationnaires pour la surveillance de la Qualité de l'AIR en Europe, in: Proceedings of Journées scientifiques mésocentres et France Grilles, http: //mesogrilles2012.sciencesconf.org/resource/page/id/12, 2012.

Hoepfner, M., Blom, C. E., Echle, G., Glatthor, N., Hase, F., and Stiller, G.: Retrieval simulations for MIPAS-STR measurements, in: IRS 2000: Current Problems in Atmospheric Radiation, edited by: Smith, W. L., Proceedings of the International Radiation Symposium, Deepak, 2001.

Kulawik, S. S., Osterman, G., Jones, D. B. A., and Bowman, K. W.: Calculation of altitude-dependent Tikhonov constraints for TES nadir retrievals, IEEE T. Geosci. Remote, 44, 1334-1342, 2006.

Lahoz, W. A., Brugge, R., Jackson, D. R., Migliorini, S., Swinbank, R., Lary, D., and Lee, A.: An Observing System Simulation Experiment to evaluate the scientific merit of wind and ozone measurements from the future SWIFT instrument, Q. J. Roy. Meteorol. Soc., 131, 503-523, 2005.

Lahoz, W. A., Peuch, V.-H., Orphal, J., Attié, J.-L., Chance, K., Liu, X., Edwards, D., Elbern, H., Flaud, J.-M., Claeyman, M., and El Amraoui, L.: Monitoring air quality from space: the case for the geostationary platform, B. Am. Meteorol. Soc., 93, 221-233, doi:10.1175/BAMS-D-11-00045.1, 2012.

Lefèvre, F., Brasseur, G. P., Folkins, I., Smith, A. K., and Simon, P.: Chemistry of the 1991-1992 stratospheric winter: three dimensional model simulations, J. Geophys. Res., 99, 8183-8195, 1994.

Masutani, M., Schlatter, T. W., Errico, R. M., Stoffelen, A., Andersson, E., Lahoz, W., Woollen, J. S., Emmitt, G. D., Riishøjgaard, L.-P., and Lord, S. J.: Observing System Simulation Experiments, in: Data Assimilation: Making Sense of Observations, edited by: Lahoz, W., Khattatov, B., and Menard, R., Springer, 647-679, 2010a.

Masutani, M., Woollen, J. S., Lord, S. J., Emmitt, G. D., Kleespies, T. J., Wood, S. A., Greco, S., Sun, H., Terry, J., Kapoor, V., Treadon, R., and Campana, K. A.: Observing system simulation experiments at the National Centers for Environmental Prediction, J. Geophys. Res., 115, D07101, doi:10.1029/2009JD012528, 2010b.
McPeters, R. D., Labow, G. J., and Logan, J. A.: Ozone climatological profiles for satellite retrieval algorithms, J. Geophys. Res., 112, D05308, doi:10.1029/2005JD006823, 2007.

Peuch, V.-H., Orphal, J., Attié, J.-L., Chance, K. V., Liu, X., Edwards, D., Elbern, H., Flaud, J.-M., Lahoz, W., Beekmann, M., Bergametti, G., Dufour, G., Eremenko, M., Brasseur, G., Buchmann, B., Builtjes, P., Carlotti, M., Ridolfi, M., Claeyman, M., Ricaud, P., von Clarmann, T., Höpfner, M., Vogel, B., Dudhia, A., El Amraoui, L., Joly, L., Josse, B., Eldering, A., Funke, B., Hov, Ø., Jacob, D., Kasai, Y., Kurosu, T. P., Lelieveld, J., Lawrence, M., Macke, A., de Maziére, M., Ménard, R., Menut, L., Palmer, P., Poisson, R., Rouill, L., Saiz-Lopez, A., Tanre, F., Warner, J., Cantié, R., Desmaziéres, Y., Maliet, E., and Pasternak, F.: MAGEAQ - Monitoring the Atmosphere from Geostationary orbit for European Air Quality: A candidate for Earth Explorer Opportunity Mission EE-8, Tech. rep., Météo-France, Toulouse, and KIT, Karlsruhe, 2010.

Rodgers, C. D.: Inverse methods for atmospheric sounding: Theory and practice, World Scientific Publishing Company, London, UK, 2000.

Sellitto, P., Dufour, G., Eremenko, M., Cuesta, J., Dauphin, P., Forêt, G., Gaubert, B., Beekmann, M., Peuch, V.-H., and Flaud, J.-M.: Analysis of the potential of one possible instrumental configuration of the next generation of IASI instruments to monitor lower tropospheric ozone, Atmos. Meas. Tech., 6, 621-635, doi:10.5194/amt-6-621-2013, 2013.

Stiller, G. P., von Clarmann, T., Funke, B., Glatthor, N., Hase, F., Höpfner, M., and Linden, A.: Sensitivity of trace gas abundances retrievals from infrared limb emission spectra to simplifying approximations in radiative transfer modelling, J. Quant. Spectrosc. Ra., 72, 249-280, doi:10.1016/S0022-4073(01)00123-6, 2002.

Stockwell, W. R., Kirchner, F., Khun, M., and Seefeld, S.: A new mechanism for regional atmospheric chemistry modelling, J. Geophys. Res., 102, 25847-25879, 1997.

Tan, D. G. H., Andersson, E., Fisher, M., and Isaksen, L.: Observing-system impact assessment using a data assimilation ensemble technique: application to the ADM-Aeolus wind profiling mission, Q. J. Roy. Meteorol. Soc., 133, 381-390, 2007.

Worden, H. M., Edwards, D. P., Deeter, M. N., Fu, D., Kulawik, S. S., Worden, J. R., and Arellano, A.: Averaging kernel prediction from atmospheric and surface state parameters based on multiple regression for nadir-viewing satellite measurements of carbon monoxide and ozone, Atmos. Meas. Tech., 6, 1633-1646, doi:10.5194/amt-6-1633-2013, 2013.

Zoogman, P., Jacob, D. J., Chance, K., Zhang, L., Sager, P. L., Fiore, A. M., Eldering, A., Liu, X., Natraj, V., and Kulawik, S. S.: Ozone air quality measurement requirements for a geostationary satellite mission, Atmos. Environ., 45, 7143-7150, doi:10.1016/j.atmosenv.2011.05.058, 2011. 